\title{
Oxidative stress impairs function and increases redox protein modifications in human spermatozoa
}

\author{
Tania Morielli ${ }^{1,2}$ and Cristian $\mathrm{O}^{\prime}$ Flaherty $^{1,2,3,4,+}$ \\ ${ }^{1}$ The Research Institute of the McGill University Health Centre, Departments of ${ }^{2}$ Surgery (Urology Division), \\ ${ }^{3}$ Obstetrics and Gynecology and ${ }^{4}$ Pharmacology and Therapeutics, McGill University, Montréal, Québec, Canada
}

Correspondence should be addressed to C O'Flaherty; Email: cristian.oflaherty@mcgill.ca

+C O'Flaherty is now at Urology Research Laboratory, Royal Victoria Hospital, Room H6.46, 687 Avenue des Pins ouest, Montréal, Québec, Canada H3A 1A1

\begin{abstract}
Oxidative stress, generated by excessive reactive oxygen species (ROS) or decreased antioxidant defenses (and possibly both), is associated with male infertility. Oxidative stress results in redox-dependent protein modifications, such as tyrosine nitration and $S$-glutathionylation. Normozoospermic sperm samples from healthy individuals were included in this study. Samples were incubated with increasing concentrations (0-5 $\mathrm{mM}$ ) of exogenous hydrogen peroxide, tert-butyl hydroperoxide, or diethylamine NONOate (DA-NONOate, a nitric oxide (NO·) donor) added to the medium. Spermatozoa treated with or without ROS were incubated under capacitating conditions and then levels of tyrosine phosphorylation and percentage of acrosome reaction (AR) induced by lysophosphatidylcholine were determined. Modified sperm proteins from cytosolic, triton-soluble, and triton-insoluble fractions were analyzed by SDS-PAGE immunoblotting and immunocytochemistry with anti-glutathione and anti-nitrotyrosine antibodies. Levels of $S$-glutathionylation increased dose dependently after exposure to hydroperoxides $(P<0.05)$ and were localized mainly to the cytosolic and triton-soluble fractions of the spermatozoa. Levels of tyrosine-nitrated proteins increased dose dependently after exposure to DA-NONOate $(P<0.05)$ and were mainly localized to the triton-insoluble fraction. ROS-treated spermatozoa showed impaired motility without affecting viability (hypo-osmotic swelling test). These treated spermatozoa had tyrosine phosphorylation and AR levels similar to that of non-capacitated spermatozoa following incubation under capacitating conditions, suggesting an impairment of sperm capacitation by oxidative stress. In conclusion, oxidative stress promotes a dose-dependent increase in tyrosine nitration and $S$-glutathionylation and alters motility and the ability of spermatozoa to undergo capacitation.
\end{abstract}

\section{Free Spanish abstract}

A Spanish translation of this abstract is freely available at http://www.reproduction-online.org/content/149/1/113/suppl/DC1. Reproduction (2015) 149 113-123

\section{Introduction}

Human infertility is an important health and a social concern, which affects $15 \%$ of couples in the reproductive age (de Kretser 1997, WHO 2010). Of these cases of infertility, $50 \%$ can be attributed to the male factor (Abid et al. 2008). Male infertility is a multifactorial disorder, which is presented clinically as low or absent sperm counts, or the presence of mutated or nonfunctional sperm cells due to abnormal spermatogenesis (Tournaye \& Cohlen 2012). This defective spermatogenesis can be linked to medical conditions such as varicocele, cryptorchidism, infections, nutritional deficiencies, or trauma. It can also be caused by exposure to environmental agents, chemotherapeutic agents, smoking, or even diseases (Brennemann et al. 1997, Hasegawa et al. 1997, Anderson \& Williamson 1988,
Smith et al. 2006). Interestingly, all the above-mentioned conditions have the oxidative stress as an important component of their pathophysiological mechanisms (Brennemann et al. 1997, Hasegawa et al. 1997, Anderson \& Williamson 1988, Turner 2001, Smith et al. 2006, Agarwal et al. 2008).

Oxidative stress is the result of an excessive production of reactive oxygen species (ROS) and/or a decrease in the antioxidant defenses (Halliwell 2006, Halliwell \& Gutteridge 2007) and targets all cell components decreasing sperm motility and mitochondrial activity (Sikka et al. 1995, Griveau \& Le Lannou 1997), promoting peroxidation of membrane lipids (Storey 1997), and DNA fragmentation and oxidation (Aitken et al. 1998, Barroso et al. 2000). The ROS-mediated damage to sperm is a significant contributing factor in $30-80 \%$ of infertile men (Gagnon et al. 1991, de Lamirande \& Gagnon 1995, 
Agarwal et al. 2006, Aitken 2006, Tremellen 2008). Low levels of antioxidant enzymes in both seminal plasma and spermatozoa are associated with impairment of sperm function, DNA integrity, and men infertility (Aitken \& Curry 2011, Gong et al. 2012).

Paradoxically, the spermatozoon requires low and controlled amounts of ROS to acquire fertilizing ability during capacitation (de Lamirande \& O'Flaherty 2012). ROS triggers most of the recognized events associated with capacitation: activation of adenylyl cyclase, increase in intracellular calcium, and phosphorylation events (protein kinases A, C, ERK, and PI3K/Akt pathways) culminating with the late tyrosine phosphorylation (Visconti et al. 1995, Leclerc et al. 1996, de O'Flaherty et al. 2006a, Lamirande \& O'Flaherty 2012). Noteworthy, failure to undergo tyrosine phosphorylation was observed in spermatozoa from infertile patients (Buffone et al. 2005). Hydrogen peroxide $\left(\mathrm{H}_{2} \mathrm{O}_{2}\right)$ affected motility (de Lamirande \& Gagnon 1992) and sperm hemizona binding (Oehninger et al. 1995) at a concentration of 0.5 or $0.2 \mathrm{mM}$ respectively. The incubation of human spermatozoa with sodium nitroprusside (a nitric oxide $(\mathrm{NO} \cdot)$ donor) promoted similar results but at higher concentrations (1 mM) (Wu et al. 2004).

$S$-glutathionylation of proteins is a post-translational modification that occurs under normal conditions as well as under conditions of oxidative stress. This modification occurs by the addition of glutathione (GSH) to cysteine residues of certain target proteins; the disulfide linkage between the glutathione and the protein is reversible affecting the functionality of enzymes, receptors, and structural proteins, thus altering normal cell biology (Halliwell \& Gutteridge 2007).

Nitrotyrosine is formed by the reaction of peroxynitrite or donors of $\mathrm{NO}$ - with tyrosine residues (Halliwell \& Gutteridge 2007). It can be produced by the sperm cell by the reaction of superoxide anion $\left(\mathrm{O}_{2}^{-}\right)$and $\mathrm{NO}$. (Herrero et al. 2001). The nitrotyrosine protein modification can result in alteration of protein function or structure and thus may affect sperm motility (Vignini et al. 2006), but is required at low amounts in the spermatozoon in order to undergo capacitation (Herrero et al. 2001).

Although it is known that high levels of ROS are detrimental for sperm motility and zona-binding ability (de Lamirande \& Gagnon 1992, Oehninger et al. 1995), there are no studies in the literature specifically elucidating the effects of ROS on the ability of human spermatozoa to undergo capacitation. Moreover, little is known regarding the promotion of redox-dependent protein modifications in human spermatozoa; thus, the objectives of this work were to determine the effect of different ROS on the production of tyrosine nitration and $S$-glutathionylation and their subcellular localization and whether an increase in modified proteins is associated with an impairment of the function of human spermatozoa.

\section{Materials and methods}

\section{Materials}

Percoll was obtained from GE Healthcare (Baie-d'Urfe, QC, Canada). Mouse monoclonal anti-glutathione antibody (clone G8) was purchased from Virogen (Watertown, MA, USA). Mouse monoclonal anti-phosphotyrosine (clone 4G10) and mouse monoclonal anti-nitrotyrosine antibodies were obtained from Upstate Biotechnology, Inc. (Lake Placid, NY, USA) and from Abcam (Toronto, ON, Canada) respectively. Donkey antirabbit immunoglobulin $\lg G$ and goat anti-mouse $\lg G$ antibodies (both conjugated with HRP) were provided by Cederlane Laboratories Ltd (Hornby, ON, Canada). Nitrocellulose membranes (pore size, $0.22 \mu \mathrm{m}$ ) were purchased from Osmonics, Inc. (Westborough, MA, USA) and the ECL Kit Lumi-Light from Roche Molecular Biochemicals. Radiographic films (obtained from Fuji; Minami-Ashigara, Japan) were used for immunodetection of blotted proteins. For immunocytochemistry studies, both biotinylated goat anti-rabbit $\lg \mathrm{G}(\mathrm{H}+\mathrm{L})$ and biotinylated horse anti-mouse $\lg \mathrm{G}(\mathrm{H}+\mathrm{L})$ were purchased from Vector Laboratories, Inc. (Burlingame, CA, USA) and Alexa Fluor 555 conjugate of streptavidin and Prolong Antifade were purchased from Life Technologies, Inc. Diethylamine NONOate (DA-NONOate) was obtained from Calbiochem (San Diego, CA, USA); Bis(dimethyl acetal), 1,4-diazabicyclo[2.2.2] octane (DABCO), and Pisum sativum agglutinin conjugated to FITC (PSA-FITC) were purchased from SigmaAldrich Chemical Co. Other chemicals used were of at least reagent grade.

\section{Subjects}

Semen samples were obtained from healthy volunteers $(n=21)$ after 3 days of sexual abstinence. This study was approved by the Ethics Board of the Royal Victoria Hospital-McGill University Health Centre, and all participants signed an informed consent form before participating. Following collection, samples were incubated at $37^{\circ} \mathrm{C}$ for $30 \mathrm{~min}$ to induce liquefaction. The liquefied semen was then analyzed by computer-assisted semen analysis system (CASA; Sperm vision HR Software v1.01, Penetrating Innovations, Ingersoll, ON, Canada) and the quality of the sample was determined according to the parameters set out by the World Health Organization guidelines (WHO 2010) (Supplementary Table 1, see section on supplementary data given at the end of this article).

\section{Sperm sample preparation}

Liquefied semen samples were centrifuged for $30 \mathrm{~min}$ at $2300 \times \mathbf{g}$ at $20{ }^{\circ} \mathrm{C}$ over a four-layer Percoll gradient (95-65$40-20 \%$, made with isotonic HEPES-balanced saline (HBS)). This step was used to separate the abnormal sperm cells, seminal plasma, and white blood cells from the sperm cells with the best motility and morphology (Kovalski et al. 1992) without increasing ROS levels (Iwasaki \& Gagnon 1992, Zini et al. 1993, Plante et al. 1994). Highly motile spermatozoa recovered from the $95 \%$ layer and the $65-95 \%$ interface were diluted to $50 \times 10^{6} \mathrm{cell} / \mathrm{ml}$ in Biggers, Whitten, and Whittingham (BWW, pH 8.0) medium (Biggers et al. 1971) and used for experimentation. 


\section{Induction of in vitro oxidative stress in spermatozoa}

Spermatozoa were incubated for $30 \mathrm{~min}$ at $37^{\circ} \mathrm{C}$ with increasing concentrations of either $\mathrm{H}_{2} \mathrm{O}_{2}$, or tert-butyl hydroperoxide (tert-BHP; a synthetic organic hydroperoxide that can produce alkoxy radical, $\mathrm{O}_{2}^{-}$, and $\mathrm{H}_{2} \mathrm{O}_{2}$ ), or Da-NONOate (NO - donor) in the BWW medium. Concentrations were selected to mimic both mild $(0.1-0.25 \mathrm{mM})$ and strong (0.5-5 mM) oxidative stress. After treatment, electrophoresis sample buffer (Tris- $\mathrm{HCl}, \mathrm{pH} 6.8$, containing 2\% SDS, $10 \%$ glycerol, $0.0025 \%$ bromophenol, $0.1 \mathrm{mM}$ vanadate, $5 \mathrm{mM}$ sodium fluoride, and $20 \mathrm{mM}$ glycerol phosphate) supplemented with or without $100 \mathrm{mM}$ dithiothreitol (DTT) was added to a $50-\mu$ l aliquot of the sperm suspension $(100 \times$ $10 \% / \mathrm{ml}$ ) of each sample. The absence of DTT in the sample buffer is indispensable to be able to see the $S$-glutathionylated proteins; as a reducing agent, DTT will cleave the glutathione from the protein and thus eliminating the signal. The rest of the aliquot was used to determine motility, viability, and ability to undergo capacitation and acrosome reaction (AR).

\section{Sperm motility and viability analysis}

Spermatozoa were subjected to oxidative stress as described previously, washed, and resuspended in the fresh BWW medium and an aliquot of $10 \times 10^{6}$ cells $/ \mathrm{ml}$ was smeared onto collodion-coated slides. Sperm motility was analyzed using the CASA system (Sperm Vision HR software v1.01, Penetrating Innovations, Ingersoll, ON, Canada) according to the WHO guidelines (WHO 2010) (Supplementary Table 1). This was achieved by averaging the motility parameters for rapid progressive, slow progressive, non-progressive, and immotile sperm, obtained from ten different fields.

Both ROS-treated and control samples were centrifuged for $5 \mathrm{~min}$ at $600 \times \boldsymbol{g}$ at $20^{\circ} \mathrm{C}$. The supernatant was removed and replaced with a hypo-osmotic solution at $37^{\circ} \mathrm{C}$ (WHO 2010). Samples were incubated for $30 \mathrm{~min}$ at $37^{\circ} \mathrm{C}$. Following this, sperm samples were gently centrifuged for $5 \mathrm{~min}$ at $1000 \times \mathbf{g}$. The supernatant was removed, and the pellet was resuspended in ethanol; the fixed cells were smeared onto superfrost plus slides, and viability was assessed by bright field microscopy to observe the presence or absence of tail curl (WHO 2010). Only sperm with a visible tail curl were considered viable and at least 200 cells were counted for each treatment.

\section{Induction of sperm capacitation}

ROS-treated spermatozoa were centrifuged for $5 \mathrm{~min}$ at $600 \times \mathbf{g}$ at $20^{\circ} \mathrm{C}$. The supernatant was then discarded and replaced with the fresh BWW medium containing either $10 \%$ fetal chord serum ultrafiltrate (FCSu), $3 \mathrm{mg} / \mathrm{ml}$ BSA, or $10 \mu \mathrm{M}$ progesterone in order to induce capacitation and spermatozoa were then incubated for $3.5 \mathrm{~h}$ at $37^{\circ} \mathrm{C}$ (O'Flaherty et al. 2004). Then, an aliquot was taken from each sample, supplemented with reducing sample buffer containing DTT as explained above, and used for immunoblotting in order to determine capacitation-associated tyrosine phosphorylation using an anti-phosphotyrosine antibody (1:10 000 dilution)
(O'Flaherty et al. 2006b). The remaining sample was centrifuged at $2000 \times \boldsymbol{g}$ for $5 \mathrm{~min}$ at $20^{\circ} \mathrm{C}$. The resulting pellet was recuperated and resuspended in the fresh BWW medium containing $2.5 \mu \mathrm{M}$ lysophosphatidylcholine (LPC) and incubated for $30 \mathrm{~min}$ at $37^{\circ} \mathrm{C}$ in order to induce the $A R$ (de Lamirande et al. 1997). In these samples, the percentage of capacitated spermatozoa was determined by the FITCconjugated Pisum sativum agglutinin staining (FITC-PSA) (de Lamirande et al. 1997). Sperm samples were centrifuged for $5 \mathrm{~min}$ at $600 \times \mathbf{g}$ at $20^{\circ} \mathrm{C}$, and fixed with ethanol. An aliquot of $10 \times 10^{6}$ cells was then smeared onto superfrost plus slides (Fischer Scientific, Montreal, QC, Canada) and air dried. Following this, slides were incubated for $5 \mathrm{~min}$ with PSAFITC. Slides were then washed with water. A 1,4-diazabicyclo [2.2.2] octane (DABCO) solution was then applied to each slide, and they were sealed with a cover slip. Slides were then observed under a Carl Zeiss (Oberkochen, Germany) Axiophot microscope (exciter filter BP450-490) at 1000 magnifications. Two hundred cells per duplicate were counted for presence or absence of an intact acrosome.

\section{Cellular fractionation and localization of tyrosine nitration and S-glutathionylation in spermatozoa}

ROS-treated spermatozoa were fractionated into cytosolic, triton-soluble, and triton-insoluble fractions as described previously (O'Flaherty \& de Souza 2011). Briefly, cells were frozen at $-80{ }^{\circ} \mathrm{C}$ for $15 \mathrm{~min}$ and then thawed at $37^{\circ} \mathrm{C}$ in order to disrupt sperm membranes and allow the release of the cytosolic content. Sperm suspensions $\left(50 \times 10^{6}\right.$ cells $\left./ \mathrm{ml}\right)$ were then centrifuged for $5 \mathrm{~min}$ at $12000 \times \boldsymbol{g}$, and the supernatant was collected. The remaining pellet was resuspended $(100 \times$ $10^{6} / \mathrm{ml}$ final concentration) in the BWW medium containing $0.2 \%$ triton $X-100$ (BWW-T) and incubated for 10 min on ice. This chilled sample was then centrifuged for $5 \mathrm{~min}$ at $12000 \times \mathbf{g}$ at $5{ }^{\circ} \mathrm{C}$, and the supernatant, containing the triton-soluble fraction, was collected. The remaining pellet (triton-insoluble fraction) was resuspended $\left(100 \times 10^{6} / \mathrm{ml}\right.$ final concentration) in BWW-T, and sonicated (three cycles of $5 \mathrm{~min}$ at $30 \%$ output) with a Sonic Vibracell (Sonics and Materials, Inc., Newtown, CT, USA) with net power output: $10 \mathrm{~W}$ and $20 \mathrm{kHz}$. The cytosolic, triton-soluble and -insoluble fractions were supplemented with a sample buffer with (reducing conditions) or without (non-reducing conditions) $100 \mathrm{mM}$ DTT and boiled for $5 \mathrm{~min}$ at $96^{\circ} \mathrm{C}$.

\section{SDS-PAGE and immunoblotting}

Aliquots of supernatant containing sperm proteins from entire spermatozoa or subcellular fractions (under non-reducing or reducing conditions) were loaded on $12 \%$ polyacrylamide gels, electrophoresed, and electrotransferred onto nitrocellulose membranes using a transfer buffer (192 mM glycine and $25 \mathrm{mM}$ Tris, $\mathrm{pH}$ 8.3) containing 20\% methanol. The membranes were then blocked via a 30-min incubation in 5\% skim milk dissolved in $2 \mathrm{mM}$ Tris ( $\mathrm{pH}$ 7.8)-buffered saline and $0.1 \%$ Tween 20 (TTBS). Membranes containing proteins under nonreducing or reducing conditions were then washed with TTBS and incubated overnight with anti-nitrotyrosine diluted 
1:10 000 or anti-glutathione diluted 1:2000 in 1\% skim milk in TTBS respectively.

Following incubation, membranes were washed by 10-min incubations in fresh TTBS. This was followed by $1-\mathrm{h}$ incubation at room temperature with a HRP-conjugated secondary antibody (1:5000 dilution). Positive immunoreactive bands were detected using chemiluminescence (Lumi-light; Roche Molecular Biochemicals). After detection, membranes were washed with distilled water and silver stained (Jacobson \& Karsnas 1990) to assure equal loading for each sample.

The relative intensity of protein bands was determined as described previously (O'Flaherty et al. 2005, Gong et al. 2012). Briefly, films with the same duration of exposure were scanned using a Hewlett Packard scanjet G4010 (Hewlett Packard) and the resulting images were analyzed using the Un-Scan-It gel Software version 5.1 (Silk Scientific Corporation, Orem, Utah). Each band's intensity was obtained and normalized to the respective intensity of the $55 \mathrm{kDa}$ band present in the membrane after staining with colloidal silver as explained above. Then, the total value of all the normalized intensity bands were obtained and again normalized with that of the control sample. Therefore, the intensity of each sample is a proportion of the intensity of the respective control for each experiment. This last normalization allowed us to determine the relative increases or decreases in intensities obtained under various experimental conditions.

\section{Immunocytochemistry}

Sperm suspensions were treated with either $5 \mathrm{mM} \mathrm{H}_{2} \mathrm{O}_{2}$ or $500 \mu \mathrm{M}$ DA-NONOate and incubated for $30 \mathrm{~min}$ at $37^{\circ} \mathrm{C}$ to induce oxidation. Aliquots containing $10 \times 10^{6}$ cells were then smeared onto superfrost plus slides (Fisher Scientific, Montreal, QC, Canada), and allowed to dry at room temperature. Dried cells were permeabilized with methanol as described previously (O'Flaherty \& de Souza 2011). Cells were rehydrated with PBS supplemented with triton $\times-100$ (PBS-T) and blocked with $5 \%$ goat serum in PBS-T for $30 \mathrm{~min}$ at $20{ }^{\circ} \mathrm{C}$. Slides were washed in PBS-T and incubated overnight at $4{ }^{\circ} \mathrm{C}$ with antinitrotyrosine or anti-glutathione antibodies. Cells were then washed and incubated for $1 \mathrm{~h}$ at $20{ }^{\circ} \mathrm{C}$ with their respective biotinylated anti-IgG antibody (dilution 3:1000). Following this, streptavidin conjugated to Alexa Fluor 555 (1:500) was applied to slides. Smears were mounted with prolong antifade and sealed with a cover slip. Negative controls were prepared in the same way, except that samples were incubated solely with the respective biotinylated anti-lgG antibody.

\section{Statistical analysis}

Percentages of capacitation, motility, and viability were transformed as arcsin square root of the proportion value and analyzed using ANOVA and the Bonferroni test. Normal distribution was confirmed using Anderson-Darling test. A difference was considered to be significant when the $P$ value was $\leq 0.05$. Systat 13 for Windows (Systat Software, Inc.) was used for all statistical analyses.

\section{Results}

\section{Impact of oxidative stress on sperm motility and viability}

We generated an in vitro mild to strong oxidative stress with exogenous sources of ROS, generating $\mathrm{H}_{2} \mathrm{O}_{2}$, alkoxy radical, $\mathrm{O}_{2}^{-}, \mathrm{NO} \cdot$, and peroxynitrite to mimic what is happening to spermatozoa of infertile men affected by high levels of ROS. A dose-dependent decrease $(P<0.05)$ in both total and progressive motilities was observed in spermatozoa treated with $\mathrm{H}_{2} \mathrm{O}_{2}$ and a significant reduction in DA-NONOatetreated spermatozoa (Fig. $1 \mathrm{~A}$ and B). A significant decrease in total motility was documented in spermatozoa treated with 0.5 and $1 \mathrm{mM}$ of $\mathrm{H}_{2} \mathrm{O}_{2}$ when compared with non-oxidized controls. In the case of sperm treated with DA-NONOate, a significant decrease was noted only after incubation with $1 \mathrm{mM}$ DA-NONOate (Fig. 1A and $\mathrm{B}$ ). Noteworthy, $\mathrm{H}_{2} \mathrm{O}_{2}$ showed a stronger negative effect on sperm motility at higher doses than DA-NONOate.

Sperm viability was then assessed using a hypoosmotic swelling test in order to determine whether the loss of motility is due to cell death. Our results confirmed that sperm viability was not affected following oxidation with both $\mathrm{H}_{2} \mathrm{O}_{2}$ and DA-NONOate (Fig. 1C).

\section{Oxidative stress impairs sperm capacitation}

Spermatozoa, treated with $\mathrm{H}_{2} \mathrm{O}_{2}$ or DA-NONOate before capacitation with FCSu01, had similar levels of tyrosine phosphorylation compared with non-capacitated controls (Fig. 2). $\mathrm{H}_{2} \mathrm{O}_{2}$ produced a greater decrease in tyrosine phosphorylation than DA-NONOate, particularly at concentrations of $1 \mathrm{mM}$. There was a dosedependent decrease in LPC-induced AR levels in spermatozoa previously treated with $\mathrm{H}_{2} \mathrm{O}_{2}$ (Fig. 3A). However, spermatozoa treated with DA-NONOate showed no change in the percentage of AR following incubation with $0.1 \mathrm{mM}$ (Fig. 3B), while this percentage drastically dropped in spermatozoa treated with 0.25 or $0.5 \mathrm{mM}$. Similar results were obtained with BSA or progesterone as capacitation inducers (data not shown).

\section{ROS promote tyrosine nitration and S-glutathionylation of sperm proteins}

Percoll-washed spermatozoa were exposed to increasing concentrations of DA-NONOate, $\mathrm{H}_{2} \mathrm{O}_{2}$, or tert-BHP (Fig. 4). DA-NONOate promoted a dose-dependent increase in the tyrosine nitration in spermatozoa (Fig. 4). Treatment with peroxides $\left(\mathrm{H}_{2} \mathrm{O}_{2}\right.$ or tert-BHP) generated a dose dependent increase in $S$-glutathionylation in spermatozoa (Fig. 5), showing a minimum or no effect on inducing the tyrosine nitration modification (Fig. 4). The levels of $S$-glutathionylation in spermatozoa treated with DA-NONOate $(0.1-1 \mathrm{mM})$ were similar to 

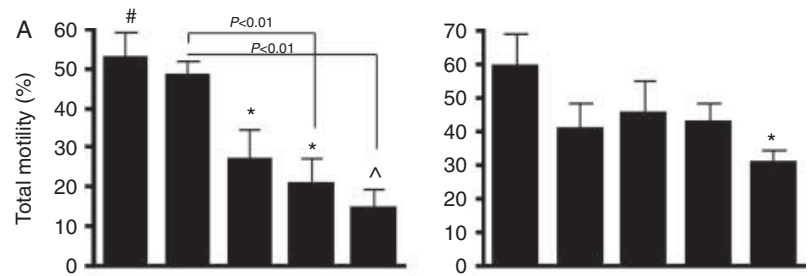

B
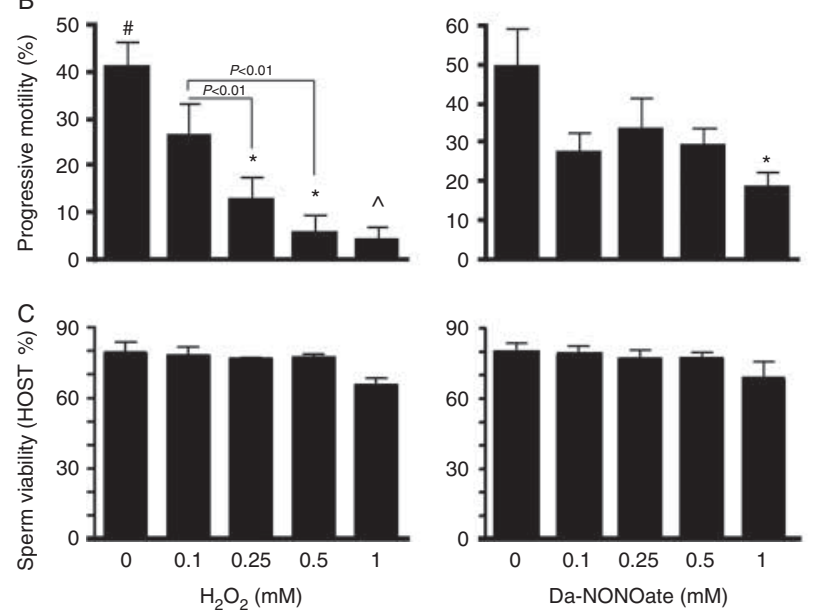

Figure 1 Total and progressive motilities decrease dose dependently in sperm treated with $\mathrm{H}_{2} \mathrm{O}_{2}$ and DA-NONOate without affecting sperm viability. The motility of sperm cells was analyzed using the CASA sperm analysis system. Total motility (A), progressive motility (B), and sperm viability $(C)$ were recorded from six different donors.

\# or $\wedge$ Means the highest and lowest values respectively. ${ }^{*}$ Lower than control $(0 \mathrm{mM})$.

those of the control and never exceeding those generated with $0.25 \mathrm{mM} \mathrm{H}_{2} \mathrm{O}_{2}$ (Fig. 6), suggesting that $\mathrm{NO} \cdot$ is not a major inducer of $S$-glutathionylation in human spermatozoa.

\section{Tyrosine nitration- and S-glutathionylation-modified proteins are differentially localized to human spermatozoa}

As exposure to high concentrations of different ROS induces an increase in the tyrosine nitration and $S$-glutathionylation (Figs 4 and 5), the next step was to determine the localization of these modified proteins within the compartments of the sperm cell. Following fractionation, we found an increase in tyrosine-nitrated proteins in all of the cytosolic, triton-soluble, and tritoninsoluble fractions following treatment with DA-NONOate (Fig. 7A). The highest levels were found in the triton-insoluble fraction. Immunocytochemistry experiments revealed a strong labeling within the tail region (Fig. 8A). Moreover, permeabilized DA-NONOatetreated spermatozoa displayed a complete labeling of the head and tail (Fig. 8, lower panel).

The majority of $S$-glutathionylated proteins were found in the cytosolic and triton-soluble fractions (Fig. 7B). Noteworthy, a strong signal was observed in proteins of high molecular mass $(\sim 170 \mathrm{kDa})$. The $\mathrm{H}_{2} \mathrm{O}_{2}$ treatment promoted the highest levels of $S$-glutathionylation in sperm proteins found in the triton-soluble fraction and with a less extent in the cytosolic fraction. The $S$-glutathionylated sperm proteins found at $170 \mathrm{kDa}$ were present in the triton-insoluble fraction. Nonpermeabilized spermatozoa displayed a strong labeling throughout the midpiece and in the post-acrosomal region (Fig. 8B). After permeabilization, a strong labeling was visible within the acrosome and throughout the tail region (Fig. 8B, lower panel). It was also noted that treatment with high concentrations of $\mathrm{H}_{2} \mathrm{O}_{2}$ caused the acrosome labeling to disappear in some cells, which may be indicative of a spontaneous AR.

\section{Discussion}

In this study, we showed evidence that oxidative stress affects sperm function differently depending on the type of ROS involved and promotes redox-dependent protein modifications that display differential localization to subcellular compartments of human spermatozoa. To our knowledge, this is the first report to extensively

A
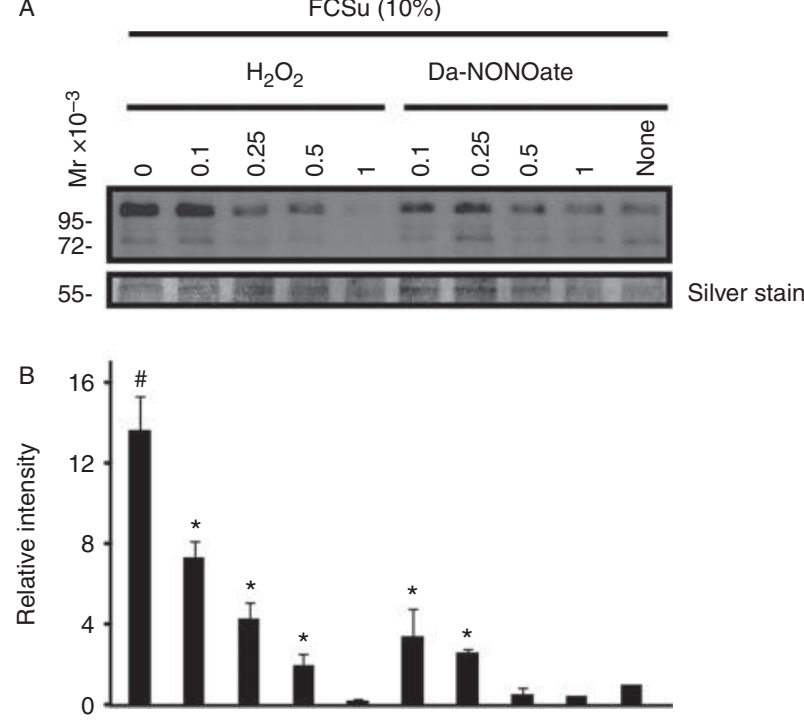

Figure 2 Spermatozoa treated with $\mathrm{H}_{2} \mathrm{O}_{2}$ or DA-NONOate showed lower levels of protein tyrosine phosphorylation after capacitation than non-oxidized controls. (A) Treated spermatozoa were capacitated for $3.5 \mathrm{~h}$ in the BWW medium, $\mathrm{pH} 8.0$, at $37^{\circ} \mathrm{C}$ supplemented without (none) or with the capacitation inducer FCSu (10\%). Sperm proteins from $0.1 \times 10^{6}$ spermatozoa were loaded in each well, electrophoresed in SDS-polyacrylamide gel under reducing conditions and immunoblotted with an anti-phosphotyrosine antibody. Silver stain was used as a loading control (band at $55 \mathrm{kDa}$ is shown in the bottom panel).

(B) Relative intensity of protein tyrosine phosphorylation. The density value of bands from sample incubated under non-capacitating conditions (none) was used to normalize the values obtained with the other samples. Relative intensity of bands is expressed as mean \pm S.E.M. Results are representative of three other experiments performed with different healthy donors $(n=4)$. "Highest value and *higher than noncapacitating control (none). 

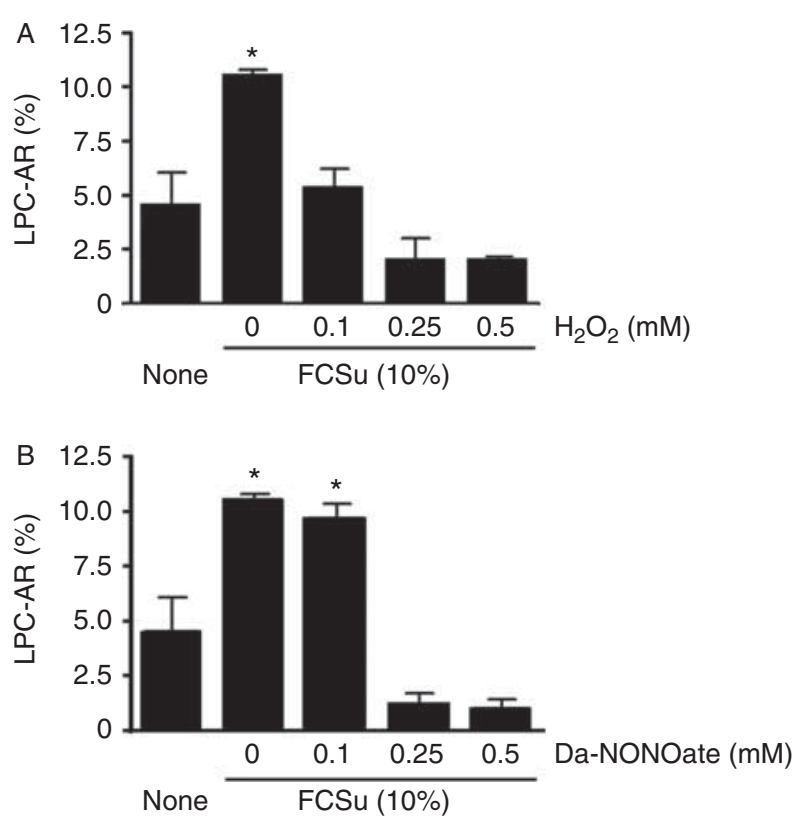

Figure 3 Oxidized spermatozoa displayed a lower level of capacitation compared with untreated controls under capacitation conditions. Spermatozoa previously treated with $\mathrm{H}_{2} \mathrm{O}_{2}$ or DA-NONOate were capacitated with FCSu for $3.5 \mathrm{~h}$ and then with LPC for $30 \mathrm{~min}$ to induce the acrosome reaction. Sperm cells were stained with PSA-FITC to visualize the acrosome, and 200 spermatozoa were observed under a fluorescent microscope. Representative blot was obtained from four other experiments performed with different donors $(n=5) .{ }^{*}$ Higher than non-capacitating control (none).

study tyrosine nitration and $S$-glutathionylation protein modifications in light of impairment of sperm motility and capacitation.

Based on the motility and viability analysis, we confirmed that the impairment of sperm motility is not due to cell death; thus, there is a direct effect of ROS on motility machinery. We examined the effect of oxidative stress on capacitation by determining the percentage of capacitated spermatozoa and the levels of tyrosine phosphorylation (Leclerc et al. 1996, O'Flaherty et al. $2006 \mathrm{~b}$ ). It was found that spermatozoa, treated with $\mathrm{H}_{2} \mathrm{O}_{2}$ before capacitation, displayed levels of tyrosine phosphorylation (Fig. 2) and LPC-induced AR (Fig. 3A) that were similar to non-capacitated controls. In the case of DA-NONOate, only concentrations higher or equal to $0.25 \mathrm{mM}$ were able to prevent both tyrosine phosphorylation and capacitation (Figs 2 and 3B). These results suggest that oxidative stress negatively affect the capability of spermatozoa to acquire fertilizing ability, thereby explaining why men with high levels of ROS in semen are infertile. The inhibition of motility and capacitation was less severe with DA-NONOate than with $\mathrm{H}_{2} \mathrm{O}_{2}$; therefore, it is important to determine which type of ROS drives the oxidative stress at the time to establish an antioxidant therapy. These results emphasize the importance of seeking ROS-targeted therapy to treat male infertility.
Peroxides $\left(\mathrm{H}_{2} \mathrm{O}_{2}\right.$ or tert-BHP) and DA-NONOate (NO donor) generated a dose-dependent increase in $S$-glutathionylation and tyrosine nitration in spermatozoa (Fig. 4), suggesting that human spermatozoa actively produce significant levels of redox-dependent protein modifications when they are challenged with an oxidative stress. These results suggest that the oxidative stress impairs motility without affecting sperm viability when high levels of tyrosine nitration and S-glutathionylation are present in human spermatozoa.

The majority of nitrated tyrosine-modified proteins were localized to the midpiece (weak labeling) and principal piece (strong labeling) of the sperm tail (Fig. 8A). We can suggest that some of these modified proteins may be present in the fiber sheath, as proteins present in these sperm structure can be found in the triton-insoluble fraction where the tyrosine-nitrated-
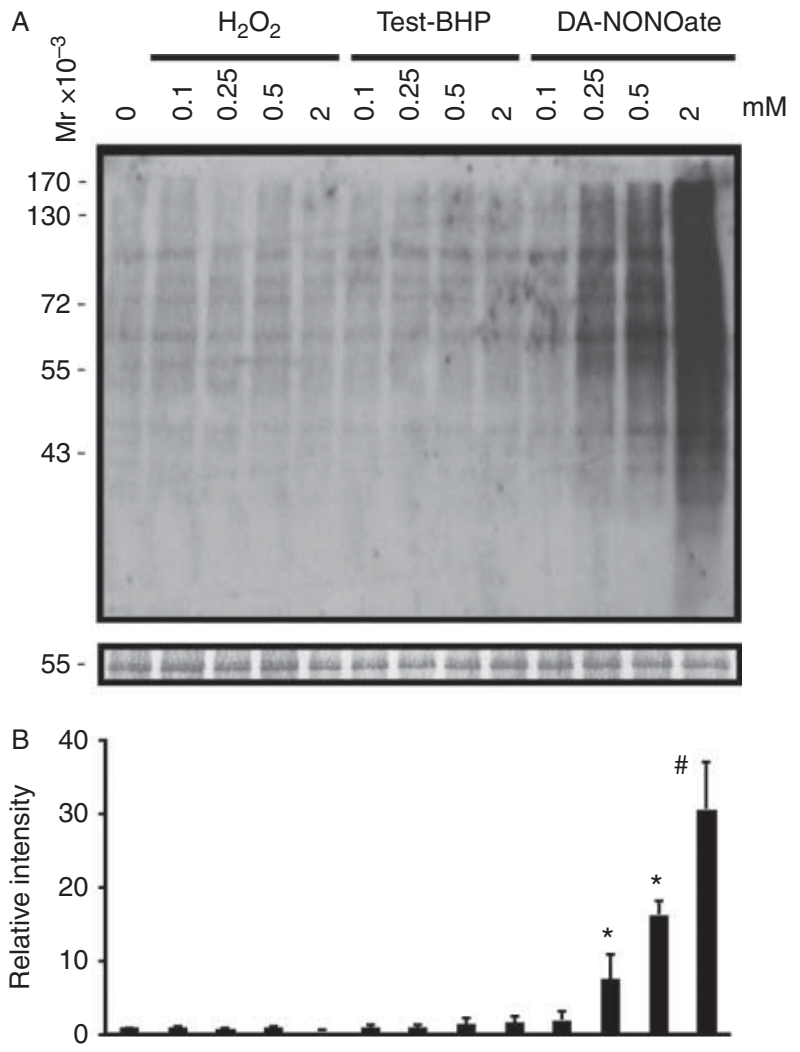

Figure 4 Dose-dependent increase in tyrosine nitration in human spermatozoa following treatment with ROS. (A) Spermatozoa were treated with increasing concentrations of $\mathrm{H}_{2} \mathrm{O}_{2}$, tert-BHP, or DA-NONOate and immunoblotted with an anti-nitrotyrosine antibody. (B) Relative intensity of tyrosine-nitrated proteins. The density value of bands obtained from a sample incubated without ROS $(0 \mathrm{mM})$ was used to normalize the values obtained with the other samples. The relative intensity of bands is expressed as mean \pm s.E.M. Membranes were silver stained to confirm equal loading between lanes (band at $55 \mathrm{kDa}$ is shown in the bottom panel). Representative blot was obtained from four other experiments performed with different donors $(n=5) .{ }^{*}$ Highest value and *higher than control $(0 \mathrm{mM})$. 
A
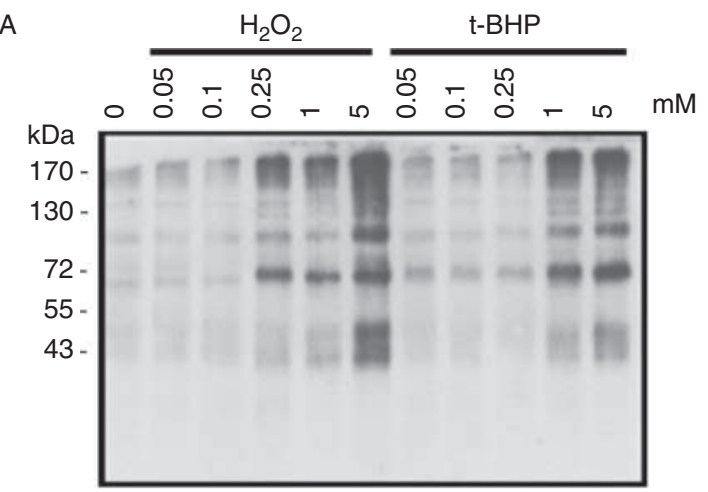

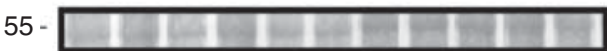

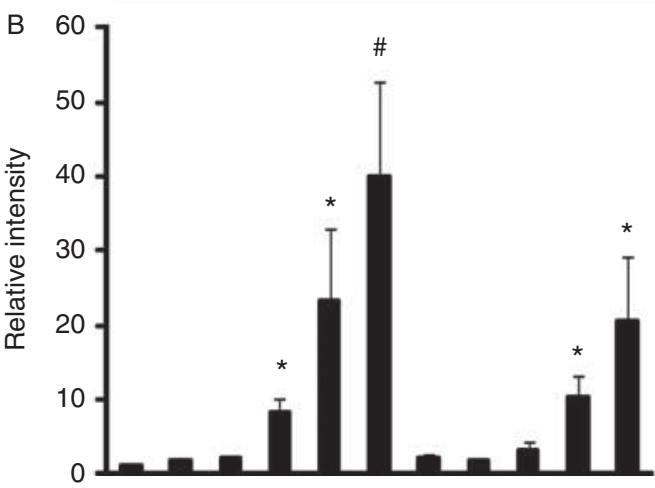

Figure 5 Dose-dependent increase in S-glutathionylation modifications in human spermatozoa following treatment with ROS. (A) Spermatozoa treated with increasing concentrations of $\mathrm{H}_{2} \mathrm{O}_{2}$ or t-BHP and immunoblotted with an anti-glutathione antibody. (B) Relative intensity of $S$-glutathionylated proteins. The density value of bands obtained from a sample incubated without ROS $(0 \mathrm{mM})$ was used to normalize the values obtained with the other samples. The relative intensity of bands is expressed as mean \pm s.E.M. ${ }^{*}$ Highest value and *higher than control $(0 \mathrm{mM})$.

modified proteins are present at high levels (Fig. 7). The decreased total and progressive motilities and the evident labeling of the tail (Figs 1 and 8A) suggest that an increase in tyrosine-nitrated-modified proteins may disrupt the function of proteins that are important for the motility machinery. While future experiments would be required to determine the identity of the modified proteins, our results suggest that glycolytic enzymes such as glyceraldehyde 3-P dehydrogenase, enolase, enzymes involved in the Krebs cycle such as aconitase, $\alpha$-ketoglutarate dehydrogenase, malate dehydrogenase, and dihydrolipoamide dehydrogenase (present in the pyruvate dehydrogenase that converts pyruvate into acetyl CoA) may be the targets as they can be altered by this modification (Lind et al. 2002, Gokulrangan et al. 2007, Shi et al. 2011; Supplementary Table 2, see section on supplementary data given at the end of this article). The evidence that sizes of bands obtained during western blot experiments for tyrosine-nitrated-modified proteins (Fig. 4 and 7A) are similar to the molecular mass of the mentioned enzymes accounts for the possibility that these energy production-related enzymes may be affected by tyrosine nitration in spermatozoa affected by oxidative stress.

We found high levels of tyrosine nitration after treatment with DA-NONOate in the head of permeabilized spermatozoa (Fig. 8). Tyrosine nitration activates metalloproteinase 9 (MMP9), promoting astrocyte migration and the subsequent inflammation of the brain under oxidative stress (Wang et al. 2011). The localization of tyrosine nitration in the sperm head is similar to that of metalloproteinases MMP2 and MMP9 found in human spermatozoa (Buchman-Shaked et al. 2002), which are suggested as important proteins for sperm zona penetration (Ferrer et al. 2012). These proteins form the extracellular coat on the inner acrosomal membrane that is exposed after AR (Ferrer et al. 2012). It is possible that premature activation of MMPs by tyrosine nitration (Wang et al. 2011) decreases the capability of the spermatozoon to penetrate the zona pellucida.

Most of the $S$-glutathionylated-modified proteins were found in the cytosolic and triton-soluble fractions (Fig. 7B). Immunocytochemistry studies revealed a strong labeling throughout the midpiece and in the post-acrosomal
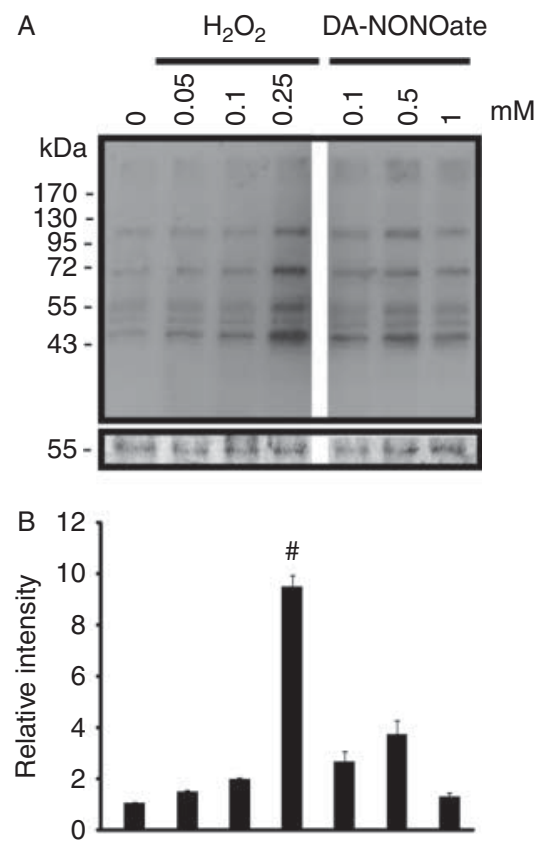

Figure 6 DA-NONOate does not increase the levels of $S$-glutathionylation in spermatozoa. (A) Spermatozoa were treated with increasing concentrations of DA-NONOate or $\mathrm{H}_{2} \mathrm{O}_{2}$ and immunoblotted with an anti-glutathione antibody. Membranes were silver stained to confirm equal loading between lanes (band at $55 \mathrm{kDa}$ is shown in the bottom panel). The density value of bands obtained from a sample incubated without ROS $(0 \mathrm{mM})$ was used to normalize the values obtained with the other samples. The relative intensity of bands is expressed as mean \pm S.E.M. All samples were loaded on the same gel. Representative blot was obtained from two other experiments performed with different donors $(n=3) .{ }^{*}$ Highest value. 
A
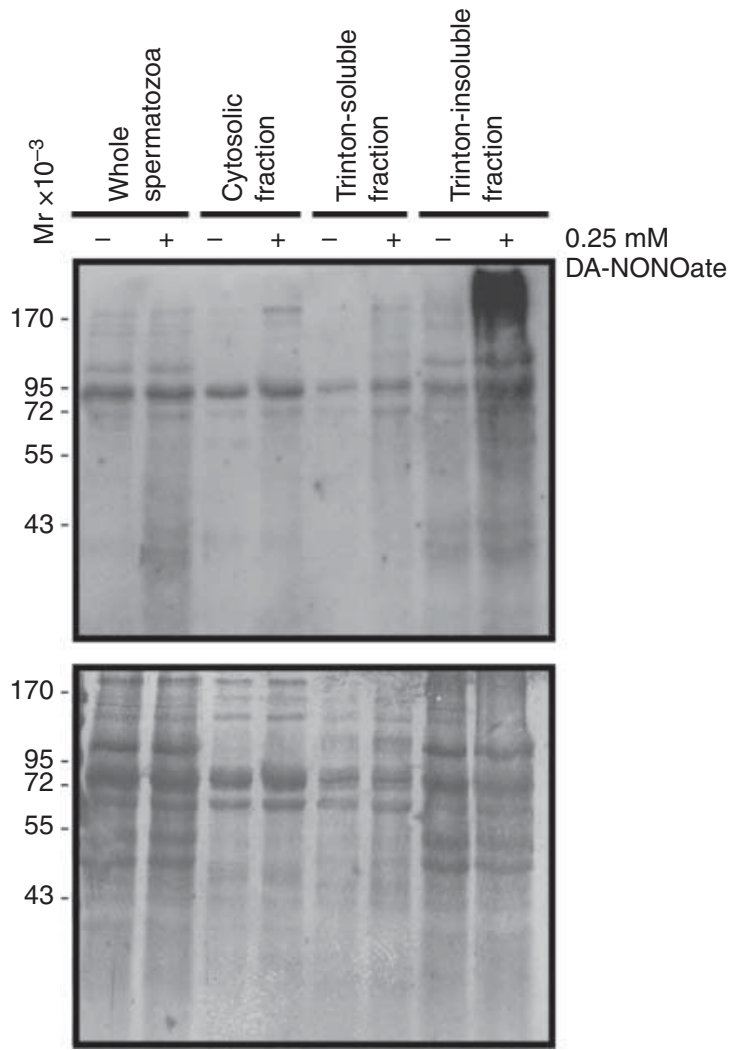

B
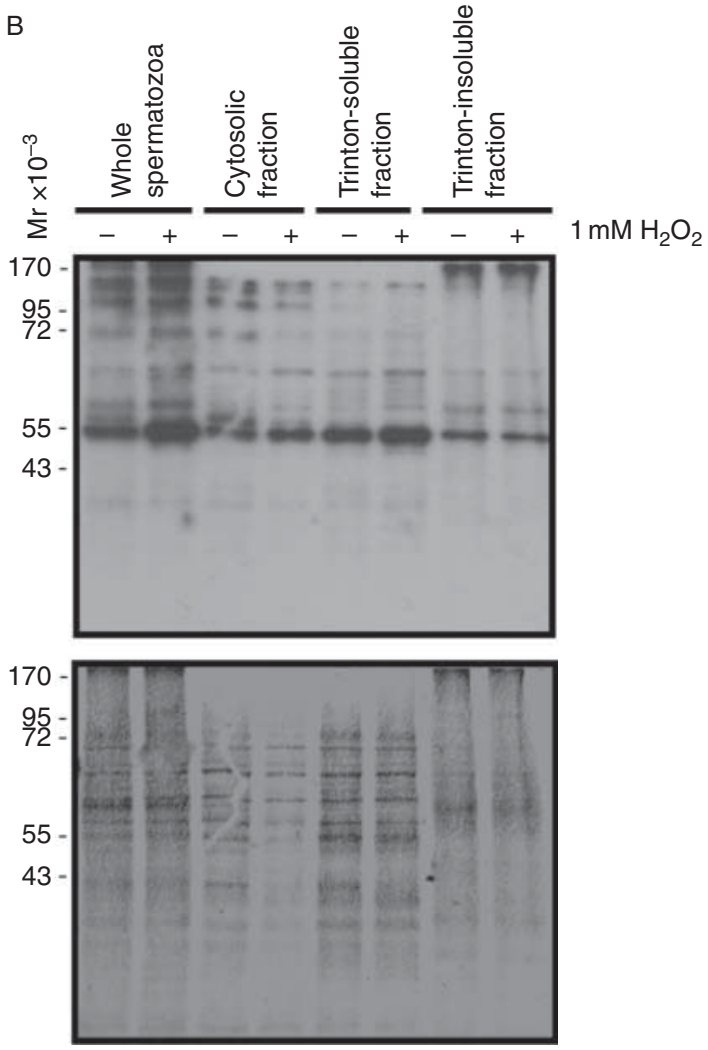

Figure 7 Tyrosine nitration and S-glutathionylation are differentially localized within the sperm cell, and most abundantly found in triton-insoluble proteins of the tail and fibrous sheath. (A) Sperm proteins treated with $0.25 \mathrm{mM}$ of DA-NONOate under reducing conditions and immunoblotted with an anti-nitrotyrosine antibody (upper panel; $0.5 \times 10^{6}$ cells were loaded for the whole and cytosolic lanes, while $1 \times 10^{6}$ cells were loaded for the triton-soluble and -insoluble lanes). (B) Sperm proteins treated with $1 \mathrm{mM} \mathrm{H}_{2} \mathrm{O}_{2}$ under non-reducing conditions and immunoblotted with an anti-GSS-R antibody (upper panel; $0.5 \times 10^{6}$ cells were loaded for the whole and cytosolic lanes, while $1 \times 10^{6}$ cells were loaded for the tritonsoluble and -insoluble lanes). Lower panels in A and B represent the respective membrane stained with colloidal gold as described in material methods. Representative blots were obtained from three other experiments performed with different donors $(n=4)$.

region (Fig. 8B). Following permeabilization, a strong labeling was visible within the acrosome and in the tail region. Within the head, components of the cytoskeleton play a role during the activation of spermatozoon; during capacitation, there is polymerization of the actin filaments that is necessary for the spermatozoon to undergo the AR (Brener et al. 2003, Breitbart et al. 2005). Actin can be $S$-glutathionylated (Dalle-Donne et al. 2003) and its modified form has been associated with Friedreich's ataxia (Pastore et al. 2003). The strong labeling in the acrosome may also be indicative of $S$-glutathionylation of actin. This redox-dependent modification of actin promotes the impossibility of actin polymerization and thus preventing the $A R$ to occur upon LPC treatment (Fig. 3).

As S-glutathionylation seemed to occur over the entire sperm cell, similar to the tyrosine nitration modification, we can also suggest that $S$-glutathionylation may impair sperm function by impeding the energy production. It has been shown that enzymes of glycolysis and of the Krebs cycle can be $S$-glutathionylated under oxidative stress (Supplementary Table 2; Fratelli et al. 2004). Noteworthy, tubulin, the major component of the sperm flagellum, can be modified by tyrosine nitration and S-glutathionylation (Landino et al. 2004); thus, our results suggest that sperm motility is affected also at the level of flagellar structure.

Oxidative stress affects human sperm function (Gagnon et al. 1991, de Lamirande \& Gagnon 1994, Agarwal et al. 2006, Aitken \& Baker 2006); however, little is known regarding the factors involved and mechanisms affected by high levels of ROS and whether various sources of oxidative stress differentially affect the sperm function. Although high levels of ROS impair motility (Aitken et al. 1998, Smith et al. 2006) and the ability to fuse with zona-free hamster oocytes (Aitken et al. 1998), and promote increased DNA damage and inhibition of capacitation (this study), the molecular mechanisms associated with these functions that are impaired by high levels of ROS are yet to be elucidated.

Besides the high sperm lipid peroxidation and DNA damage, it has been recently suggested that the antioxidant enzymes, peroxiredoxins (PRDXs), are highly oxidized and thus inactive in infertile patients (Gong et al. 2012). PRDXs are highly abundant and differentially distributed in all sub-compartments of the 

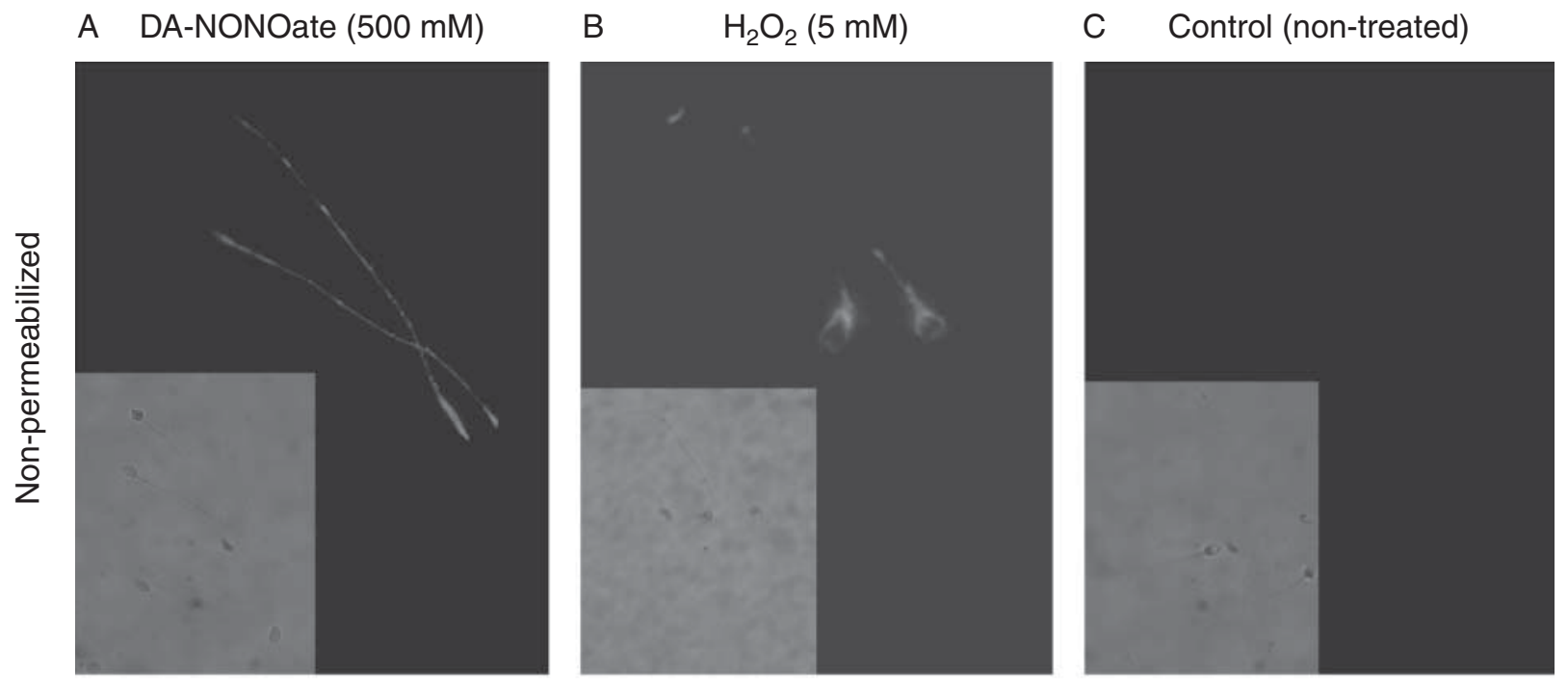

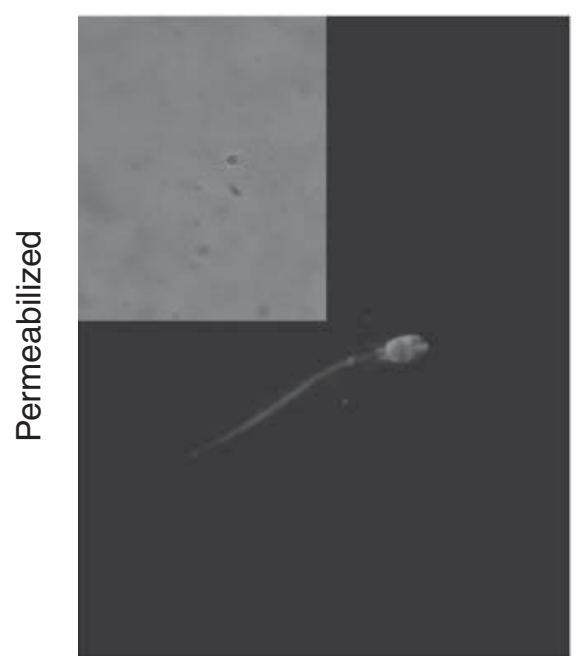

Tyr-nitration

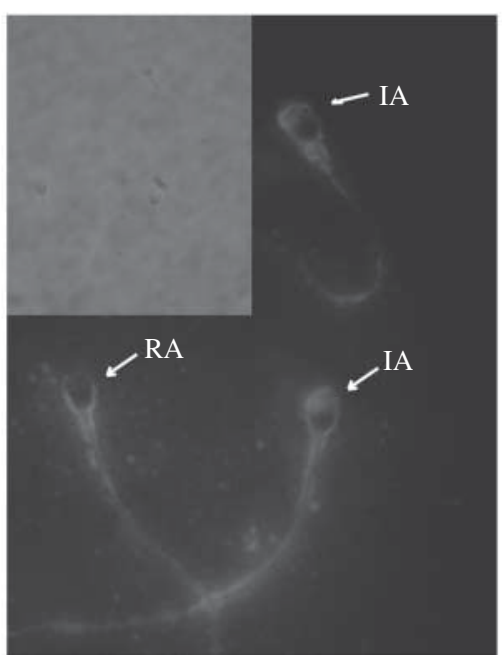

S-glutathionylation

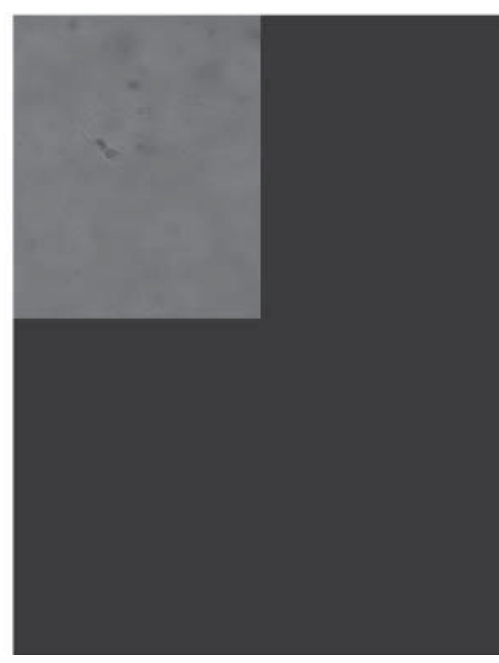

Anti-Nitro Tyrn or Anti-GSH antibodies

Figure $8 \mathrm{~S}$-glutathionylated proteins were differentially localized within the sperm cell and preferentially found within the triton-soluble and cytosolic fractions. Immunocytochemistry images were taken by fluorescence and phase-contrast microscopy at $1000 \times$ magnification for sperm treated with $500 \mu \mathrm{M}$ DA-NONOate (A) or with $5 \mathrm{mM}$ of $\mathrm{H}_{2} \mathrm{O}_{2}$ (B). Treated and untreated sperm were photographed at the same time of exposure. Absence of unspecific labeling by the secondary antibody was also confirmed (data not shown) $(n=4)$.

human spermatozoon and are considered the first line of defense against oxidative stress in human spermatozoa (O'Flaherty \& de Souza 2011). Our laboratory reported that PRDX1 and PRDX6 form $\sim 170 \mathrm{kDa}$ protein complexes detected in spermatozoa treated with high concentrations of $\mathrm{H}_{2} \mathrm{O}_{2}(0.25-5 \mathrm{mM})$ and also in spermatozoa from infertile men (O'Flaherty \& de Souza 2011, Gong et al. 2012). There is increasing evidence supporting the involvement of PRDXs in the regulation of redox signaling, especially $\mathrm{H}_{2} \mathrm{O}_{2}$-dependent signaling (Rhee et al. 2005, Fourquet et al. 2008). As oxidative stress promotes $S$-glutathionylation of PRDXs (Lind et al. 2002, Noguera-Mazon et al. 2006) and we found $130-170 \mathrm{kDa}$ bands with high levels of $S$-glutathionylation, it is possible that $S$-glutathionylation of PRDX1 and PRDX6 worsens the impairment of sperm function observed in this and previous studies (O'Flaherty \& de Souza 2011, Gong et al. 2012). It is noteworthy that the strong signal of tyrosine nitration and $S$-glutathionylation on the sperm head (Fig. 8) corresponds with the localization of PRDXs (O'Flaherty \& de Souza 2011, O'Flaherty 2014). It is then plausible that the redox-dependent modifications of PRDXs are causing the increase in levels of sperm DNA damage observed in infertile men (Gong et al. 2012). We have recently found that male mice lacking $\operatorname{Prd} \times 6$ show high levels of DNA fragmentation and oxidation (Ozkosem \& O'Flaherty 2012); these data provide evidence in support of the role of PRDXs and particularly PRDX6 in the protection of paternal genome against oxidative stress. 
In conclusion, tyrosine nitration and S-glutathionylation increase dose dependently in spermatozoa after treatment with ROS, and they are differentially localized within spermatozoa. The oxidative stress prevents spermatozoa from undergoing capacitation, impairs sperm motility, and increases tyrosine nitration and $S$-glutathionylation. Excessive levels of tyrosine nitration and $S$-glutathionylation of specific sperm proteins may be involved in the pathological mechanisms leading to impairment of sperm function.

\section{Supplementary data}

This is linked to the online version of the paper at http://dx.doi. org/10.1530/REP-14-0240.

\section{Declaration of interest}

The authors declare that there is no conflict of interest that could be perceived as prejudicing the impartiality of the research reported.

\section{Funding}

This study was supported by the Canadian Institutes of Health Research (MOP 133661), the Fonds de Recherché en Santé Quebec (FRSQS \#22151), and a Chercheur Boursier Junior 1 Salary Award from FRSQS (20482) to C O'Flaherty and a studentship from the Research Institute-MUHC (\#4696) to T Morielli.

\section{Acknowledgements}

The authors thank donors who participated in this study.

\section{References}

Abid S, Maitra A, Meherji P, Patel Z, Kadam S, Shah J, Shah R, Kulkarni V, Baburao V \& Gokral J 2008 Clinical and laboratory evaluation of idiopathic male infertility in a secondary referral center in India. Journal of Clinical Laboratory Analysis 22 29-38. (doi:10.1002/ jcla.20216)

Agarwal A, Gupta S \& Sikka S 2006 The role of free radicals and antioxidants in reproduction. Current Opinion in Obstetrics \& Gynecology 18 325-332. (doi:10.1097/01.gco.0000193003.58158.4e)

Agarwal A, Makker K \& Sharma R 2008 Clinical relevance of oxidative stress in male factor infertility: an update. American Journal of Reproductive Immunology 59 2-11. (doi:10.1111/j.1600-0897.2007. 00559.x)

Aitken RJ 2006 Sperm function tests and fertility. International Journal of Andrology 29 69-75. (doi:10.1111/j.1365-2605.2005.00630.x)

Aitken RJ \& Baker MA 2006 Oxidative stress, sperm survival and fertility control. Molecular and Cellular Endocrinology 250 66-69. (doi:10. 1016/j.mce.2005.12.026)

Aitken RJ \& Curry BJ 2011 Redox regulation of human sperm function: from the physiological control of sperm capacitation to the etiology of infertility and DNA damage in the germ line. Antioxidants \& Redox Signaling 14 367-381. (doi:10.1089/ars.2010.3186)

Aitken RJ, Gordon E, Harkiss D, Twigg JP, Milne P, Jennings Z \& Irvine DS 1998 Relative impact of oxidative stress on the functional competence and genomic integrity of human spermatozoa. Biology of Reproduction 59 1037-1046. (doi:10.1095/biolreprod59.5.1037)
Anderson JB \& Williamson RC 1988 Testicular torsion in Bristol: a 25-year review. British Journal of Surgery 75 988-992. (doi:10.1002/bjs.1800751015)

Barroso G, Morshedi M \& Oehninger S 2000 Analysis of DNA fragmentation, plasma membrane translocation of phosphatidylserine and oxidative stress in human spermatozoa. Human Reproduction 15 1338-1344. (doi:10.1093/humrep/15.6.1338)

Biggers JD, Whitten WK \& Whittngham DG 1971 The culture of mouse embryos in vitro. In Methods in Mammalian Embryology, pp 86-116. Ed. JC Daniel. San Francisco, CA: Freeman.

Breitbart H, Cohen G \& Rubinstein S 2005 Role of actin cytoskeleton in mammalian sperm capacitation and the acrosome reaction. Reproduction 129 263-268. (doi:10.1530/rep.1.00269)

Brener E, Rubinstein S, Cohen G, Shternall K, Rivlin J \& Breitbart H 2003 Remodeling of the actin cytoskeleton during mammalian sperm capacitation and acrosome reaction. Biology of Reproduction 68 837-845. (doi:10.1095/biolreprod.102.009233)

Brennemann W, Stoffel-Wagner B, Helmers A, Mezger J, Jager N \& Klingmuller D 1997 Gonadal function of patients treated with cisplatin based chemotherapy for germ cell cancer. Journal of Urology $\mathbf{1 5 8}$ 844-850. (doi:10.1016/S0022-5347(01)64333-7)

Buchman-Shaked O, Kraiem Z, Gonen Y \& Goldman S 2002 Presence of matrix metalloproteinases and tissue inhibitor of matrix metalloproteinase in human sperm. Journal of Andrology 23 702-708.

Buffone MG, Calamera JC, Verstraeten SV \& Doncel GF 2005 Capacitation-associated protein tyrosine phosphorylation and membrane fluidity changes are impaired in the spermatozoa of asthenozoospermic patients. Reproduction 129 697-705. (doi:10.1530/rep.1.00584)

Dalle-Donne I, Rossi R, Giustarini D, Colombo R \& Milzani A 2003 Actin $S$-glutathionylation: evidence against a thiol-disulphide exchange mechanism. Free Radical Biology \& Medicine 35 1185-1193. (doi:10. 1016/S0891-5849(03)00504-5)

Ferrer M, Rodriguez H, Zara L, Yu Y, Xu W \& Oko R 2012 MMP2 and acrosin are major proteinases associated with the inner acrosomal membrane and may cooperate in sperm penetration of the zona pellucida during fertilization. Cell and Tissue Research 349 881-895. (doi:10.1007/s00441-012-1429-1)

Fourquet S, Huang ME, D'Autreaux B \& Toledano MB 2008 The dual functions of thiol-based peroxidases in $\mathrm{H}_{2} \mathrm{O}_{2}$ scavenging and signaling. Antioxidants \& Redox Signaling 10 1565-1576. (doi:10.1089/ars.2008. 2049)

Fratelli M, Gianazza E \& Ghezzi P 2004 Redox proteomics: identification and functional role of glutathionylated proteins. Expert Review of Proteomics $1365-376$. (doi:10.1586/14789450.1.3.365)

Gagnon C, Iwasaki A, de Lamirande E \& Kovalski N 1991 Reactive oxygen species and human spermatozoa. Annals of the New York Academy of Sciences 637 436-444. (doi:10.1111/j.1749-6632.1991.tb27328.x)

Gokulrangan G, Zaidi A, Michaelis ML \& Schoneich C 2007 Proteomic analysis of protein nitration in rat cerebellum: effect of biological aging. Journal of Neurochemistry 100 1494-1504. (doi:10.1111/j.1471-4159. 2006.04334.x)

Gong S, San Gabriel M, Zini A, Chan P \& O'Flaherty C 2012 Low amounts and high thiol oxidation of peroxiredoxins in spermatozoa from infertile men. Journal of Andrology 33 1342-1351. (doi:10.2164/jandrol.111. 016162)

Griveau JF \& Le Lannou D 1997 Reactive oxygen species and human spermatozoa: physiology and pathology. International Journal of Andrology 20 61-69. (doi:10.1046/j.1365-2605.1997.00044.x)

Halliwell B 2006 Oxidative stress and neurodegeneration: where are we now? Journal of Neurochemistry 97 1634-1658. (doi:10.1111/j.14714159.2006.03907.x)

Halliwell B \& Gutteridge J 2007 Cellular responses to oxidative stress: adaptation, damage, repair, senescence and death. In Free Radicals in Biology and Medicine, pp 187-267. Eds B Halliwell\& J Gutteridge. New York: Oxford University Press.

Hasegawa M, Wilson G, Russell LD \& Meistrich ML 1997 Radiationinduced cell death in the mouse testis: relationship to apoptosis. Radiation Research 147 457-467. (doi:10.2307/3579503)

Herrero MB, de Lamirande E \& Gagnon C 2001 Tyrosine nitration in human spermatozoa: a physiological function of peroxynitrite, the reaction product of nitric oxide and superoxide. Molecular Human Reproduction 7 913-921. (doi:10.1093/molehr/7.10.913) 
Iwasaki A \& Gagnon C 1992 Formation of reactive oxygen species in spermatozoa of infertile patients. Fertility and Sterility $\mathbf{5 7} 409-416$.

Jacobson G \& Karsnas P 1990 Important parameters in semi-dry electrophoretic transfer. Electrophoresis 11 46-52. (doi:10.1002/elps.1150110111)

Kovalski NN, de Lamirande E \& Gagnon C 1992 Reactive oxygen species generated by human neutrophils inhibit sperm motility: protective effect of seminal plasma and scavengers. Fertility and Sterility 58 809-816.

de Lamirande E \& O'Flaherty C 2012 Sperm capacitation as an oxidative event. In Studies on Men's Health and Fertility, Oxidative Stress in Applied Basic Research and Clinical Practice, pp 57-94. Eds J Aitken, J Alvarez\& A Agawarl. Springer Science. (doi:10.1007/978-1-61779776-7_4)

de Kretser DM 1997 Male infertility. Lancet 349 787-790. (doi:10.1016/ S0140-6736(96)08341-9)

de Lamirande E \& Gagnon C 1992 Reactive oxygen species and human spermatozoa. I. Effects on the motility of intact spermatozoa and on sperm axonemes. Journal of Andrology 13 368-378. (doi:10.1002/ j.1939-4640.1992.tb03327.x)

de Lamirande E \& Gagnon C 1994 Reactive oxygen species (ROS) and reproduction. Advances in Experimental Medicine and Biology 366 185-197. (doi:10.1007/978-1-4615-1833-4_14)

de Lamirande E \& Gagnon C 1995 Impact of reactive oxygen species on spermatozoa: a balancing act between beneficial and detrimental effects. Human Reproduction 10 (Suppl 1) 15-21. (doi:10.1093/humrep/10. suppl_1.15)

de Lamirande E, Leclerc P \& Gagnon C 1997 Capacitation as a regulatory event that primes spermatozoa for the acrosome reaction and fertilization. Molecular Human Reproduction 3 175-194. (doi:10.1093/molehr/3.3.175)

Landino LM, Iwig JS, Kennett KL \& Moynihan KL 2004 Repair of peroxynitrite damage to tubulin by the thioredoxin reductase system. Free Radical Biology \& Medicine 36 497-506. (doi:10.1016/j.freeradbiomed.2003.11.026)

Leclerc P, de Lamirande E \& Gagnon C 1996 Cyclic adenosine $3^{\prime}, 5^{\prime}$ monophosphate-dependent regulation of protein tyrosine phosphorylation in relation to human sperm capacitation and motility. Biology of Reproduction 55 684-692. (doi:10.1095/biolreprod55.3.684)

Lind C, Gerdes R, Hamnell Y, Schuppe-Koistinen I, von Löwenhielm HB, Holmgren A \& Cotgreave IA 2002 Identification of S-glutathionylated cellular proteins during oxidative stress and constitutive metabolism by affinity purification and proteomic analysis. Archives of Biochemistry and Biophysics 406 229-240. (doi:10.1016/S0003-9861(02)00468-X)

Noguera-Mazon V, Lemoine J, Walker O, Rouhier N, Salvador A, Jacquot JP, Lancelin JM \& Krimm I 2006 Glutathionylation Induces the dissociation of 1-Cys D-peroxiredoxin non-covalent homodimer. Journal of Biological Chemistry 281 31736-31742. (doi:10.1074/jbc. M602188200)

Oehninger S, Blackmore P, Mahony M \& Hodgen G 1995 Effects of hydrogen peroxide on human spermatozoa. Journal of Assisted Reproduction and Genetics 12 41-47. (doi:10.1007/BF02214128)

O'Flaherty C 2014 Peroxiredoxins: hidden players in the antioxidant defence of human spermatozoa. Basic and Clinical Andrology 244. (doi:10.1186/2051-4190-24-4)

O'Flaherty C \& de Souza AR 2011 Hydrogen peroxide modifies human sperm peroxiredoxins in a dose-dependent manner. Biology of Reproduction 84 238-247. (doi:10.1095/biolreprod.110.085712)

O'Flaherty C, de Lamirande E \& Gagnon C 2004 Phosphorylation of the arginine-X-X-(serine/threonine) motif in human sperm proteins during capacitation: modulation and protein kinase A dependency. Molecular Human Reproduction 10 355-363. (doi:10.1093/molehr/gah046)

O'Flaherty C, de Lamirande E \& Gagnon C 2005 Reactive oxygen species and protein kinases modulate the level of phospho-MEK-like proteins during human sperm capacitation. Biology of Reproduction 73 94-105. (doi:10.1095/biolreprod.104.038794)

O'Flaherty C, de Lamirande E \& Gagnon C 2006a Positive role of reactive oxygen species in mammalian sperm capacitation: triggering and modulation of phosphorylation events. Free Radical Biology \& Medicine 41 528-540. (doi:10.1016/j.freeradbiomed.2006.04.027)

O'Flaherty C, de Lamirande E \& Gagnon C 2006b Reactive oxygen species modulate independent protein phosphorylation pathways during human sperm capacitation. Free Radical Biology \& Medicine 40 1045-1055. (doi:10.1016/j.freeradbiomed.2005.10.055)
Ozkosem B \& O'Flaherty C 2012 Detrimental effects of oxidative stress on spermatozoa lacking peroxiredoxin 6. Free Radical Biology \& Medicine 53 S86. (doi:10.1016/j.freeradbiomed.2012.10.345)

Pastore A, Tozzi G, Gaeta LM, Bertini E, Serafini V, Cesare SD, Bonetto V, Casoni F, Carrozzo R, Federici G et al. 2003 Actin glutathionylation increases in fibroblasts of patients with Friedreich's ataxia. Journal of Biological Chemistry 278 42588-42595. (doi:10.1074/jbc.M3018 72200)

Plante M, de Lamirande E \& Gagnon C 1994 Reactive oxygen species released by activated neutrophils, but not by deficient spermatozoa, are sufficient to affect normal sperm motility. Fertility and Sterility $\mathbf{6 2}$ 387-393.

Rhee SG, Chae HZ \& Kim K 2005 Peroxiredoxins: a historical overview and speculative preview of novel mechanisms and emerging concepts in cell signaling. Free Radical Biology \& Medicine 38 1543-1552. (doi:10. 1016/j.freeradbiomed.2005.02.026)

Shi Q, Xu H, Yu H, Zhang N, Ye Y, Estevez AG, Deng H \& Gibson GE 2011 Inactivation and reactivation of the mitochondrial $\alpha$-ketoglutarate dehydrogenase complex. Journal of Biological Chemistry 286 17640-17648. (doi:10.1074/jbc.M110.203018)

Sikka SC, Rajasekaran M \& Hellstrom WJ 1995 Role of oxidative stress and antioxidants in male infertility. Journal of Andrology 16 464-468. (doi:10.1002/j.1939-4640.1995.tb00566.x)

Smith R, Kaune H, Parodi D, Madariaga M, Rios R, Morales I \& Castro A 2006 Increased sperm DNA damage in patients with varicocele: relationship with seminal oxidative stress. Human Reproduction 21 986-993. (doi:10.1093/humrep/dei429)

Storey BT 1997 Biochemistry of the induction and prevention of lipoperoxidative damage in human spermatozoa. Molecular Human Reproduction 3 203-213. (doi:10.1093/molehr/3.3.203)

Tournaye HJ \& Cohlen BJ 2012 Management of male-factor infertility. Best Practice \& Research. Clinical Obstetrics \& Gynaecology 26 769-775. (doi:10.1016/j.bpobgyn.2012.05.005)

Tremellen K 2008 Oxidative stress and male infertility: a clinical perspective. Human Reproduction Update 14 243-258. (doi:10.1093/ humupd/dmn004)

Turner TT 2001 The study of varicocele through the use of animal models. Human Reproduction Update 7 78-84. (doi:10.1093/humupd/7.1.78)

Vignini A, Nanetti L, Buldreghini E, Moroni C, Ricciardo-Lamonica G, Mantero F, Boscaro M, Mazzanti L \& Balercia G 2006 The production of peroxynitrite by human spermatozoa may affect sperm motility through the formation of protein nitrotyrosine. Fertility and Sterility 85 947-953. (doi:10.1016/j.fertnstert.2005.09.027)

Visconti PE, Bailey JL, Moore GD, Pan D, Olds-Clarke P \& Kopf GS 1995 Capacitation of mouse spermatozoa. I. Correlation between the capacitation state and protein tyrosine phosphorylation. Development 121 1129-1137.

Wang HH, Hsieh HL \& Yang CM 2011 Nitric oxide production by endothelin-1 enhances astrocytic migration via the tyrosine nitration of matrix metalloproteinase-9. Journal of Cellular Physiology $\mathbf{2 2 6}$ 2244-2256. (doi:10.1002/jcp.22560)

World Health Organization 2010 WHO Laboratory Manual for the Examination and Processing of Human Semen. WHO Press,.

Wu TP, Huang BM, Tsai HC, Lui MC \& Liu MY 2004 Effects of nitric oxide on human spermatozoa activity, fertilization and mouse embryo development. Systems Biology in Reproductive Medicine 50 173-179. (doi:10. 1080/01485010490455494)

Zini A, de Lamirande E \& Gagnon C 1993 Reactive oxygen species in semen of infertile patients: levels of superoxide dismutase- and catalaselike activities in seminal plasma and spermatozoa. International Journal of Andrology 16 183-188. (doi:10.1111/j.1365-2605.1993. tb01177.x)

Received 5 May 2014

First decision 10 June 2014

Revised manuscript received 10 October 2014

Accepted 28 October 2014 